\title{
Analytical vs Numerical Calculation of Fatigue Life for Different Welded Joint Regions
}

\author{
Abubkr M. HEMER, Mihajlo ARANDJELOVIĆ*, Ljubica MILOVIĆ, Milan KLJAJIN, Jasmina LOZANOVIĆ ŠAJIĆ
}

\begin{abstract}
This research will show the analytical way of determining the remaining life of a welded joint with a fatigue crack initiated in its heat affected zone. The calculation will be divided into two stages, since the fatigue crack propagated through the heat affected zone, and then through the parent material. The analysis will be related to specimens with different fatigue properties taken into account for both regions. These calculations included a number of models, since different crack lengths were used for the heat affected zone and the parent material. There were three pairs of different HAZ vs PM fatigue crack lengths, always with the assumption that the total crack length is $5 \mathrm{~mm}$, due to measuring range of the used measuring foils. The aim of this analysis was to apply method typically used in fracture mechanics in order to determine the number of cycles in a welded joint with an initiated fatigue crack, depending on a number of parameters. Obtained results were then compared to the results from the numerical analysis for the same cases. While the total number of cycles was mostly unaffected by these changes, some noticeable differences were observed between individual welded joint regions in question, the heat affected zone and the parent material.
\end{abstract}

Keywords: fatigue life; fracture mechanics; welded joint region

\section{INTRODUCTION}

The work presented here was largely inspired by various fatigue analyses that were carried out recently. Some of them were involved in the crack propagation in terms of each individual welded joint region [1-9]. The influence of different microstructures, i.e. different welded joint regions on fracture behaviour of welded joints became an interesting research topic in the field of fracture mechanics [1, 10-14], and this recent interest in it inspired the work presented here. The goal was to expand the methodology developed in [1] to numerical simulations which would involve different types of materials for welded joints. Even when only focusing on steels, different groups of steels can have significantly different relationships between their welded joint regions in terms of mechanical properties, which results in a number of different possibilities for their behaviour in the presence of cracks. The cases considered here involved a fatigue crack initiated in the heat affected zone of a welded joint, [14]. Although fatigue is not the primary concern when it comes to this steel applications, there were two reasons why it was selected for this analysis-previous work involved a microalloyed high strength steel, so the goal was to select a steel with significantly different microstructure, i.e. mechanical and fatigue properties; also, relevant experimental results for this steel were readily available [14]. In addition, one should keep in mind potential applications in problems addressed in some of the previous references.

Following the numerical simulations, numbers of cycles were also determined analytically for the same models, in order to compare them. Since the fatigue crack in this case would propagate through both the heat affected zone and the parent material (due to welded joint geometry), each of these regions was analysed separately, taking into account its corresponding crack length. There was a total of three HAZ and PM model combinations, with slightly increased HAZ/decreased PM crack length and vice versa, whereas the total crack length was always $5 \mathrm{~mm}$ (due to the measuring foils used, RMF 5) [15].

\section{ANALYTICAL PROCEDURE}

The analytical determining of the number of cycles under fatigue load was based on the procedure shown in [16]. In order to carry out this analysis, the following parameters were required:

- $\quad$ Paris coefficients $C$ and $m$,

- Stress ratio

- $\quad$ Static and amplitude stresses

- Initial crack length,

- Critical crack length,

- Crack geometry factor, 1.12 in this case [17].

Paris coefficients were adopted from experimental data, as is common practice $[1,2]$. In this case, coefficient $C$ corresponds in $\mathrm{MPa} \cdot \sqrt{\mathrm{mm}}$ units.

The stress ratio in this case was to determine the amplitude stresses that would occur in each model. The procedure for determining these stresses is as follows:

Static stress was calculated based on the bending moments from the experiment and the load-bearing crosssection of the specimen.

This cross-section depended on the initial crack length and was also decreased by the presence of the $1.4 \mathrm{~mm}$ notch. For HAZ models, cross-section was always the same, for PM models it varied depending on the initial crack length, i.e. the final crack length from the HAZ.

The applied load also depended on the model-for HAZ it was always the starting value of the bending moment from the experiment, for the PM the value corresponding to its relevant initial crack length was adopted (showing small, but non-negligible differences).

Amplitude stresses were then determined based on the static stresses and the stress ratio. The stress ratio was 0.1 and it corresponds to the ratio of minimum and maximum stresses. Considering this, along with the fact that the minimum stress equals static stress minus the amplitude stress (maximum stress is obtained by summing the two), it was easy to determine the values of amplitude stresses, as the only unknown value in this case.

- The geometry factor, as the name suggests, depends on the shape and position of the crack in the loaded structure. In the case of a surface edge crack, which was adopted here, this value is typically adopted as 1.12 [17]. 
Values of static and amplitude stresses, required for the analytical calculation of fatigue life are shown in Tab. 1. Additionally, Tab. 1 shows the crack length combinations that were considered $2.2 \mathrm{~mm} \mathrm{HAZ}+2.8 \mathrm{PM}$, $2.4 \mathrm{~mm} \mathrm{HAZ}+2.6 \mathrm{~mm}$ PM and $2.65 \mathrm{~mm} \mathrm{HAZ}$ and 2.35 PM. These were the lengths originally used in the numerical analyses. As can be seen, the total crack length was always assumed to be $5 \mathrm{~mm}$, for reasons previously explained. As for the initial fatigue crack length in the HAZ, it was assumed as $0.2 \mathrm{~mm}$ in all three cases.

Table 1 Static and amplitude stresses for each welded joint region model

\begin{tabular}{|c|c|c|}
\hline Zone & $\begin{array}{c}\text { Static stress } \\
/ \mathrm{MPa}\end{array}$ & $\begin{array}{c}\text { Amplitude stress } \\
/ \mathrm{MPa}\end{array}$ \\
\hline $\begin{array}{c}2.2 \mathrm{~mm} \mathrm{HAZ,} 2.4 \mathrm{~mm} \mathrm{HAZ}, \\
2.65 \mathrm{~mm} \mathrm{HAZ}\end{array}$ & 160 & 130.9 \\
\hline $2.8 \mathrm{~mm} \mathrm{PM}$ & 144 & 117.8 \\
\hline $2.6 \mathrm{~mm} \mathrm{PM}$ & 143.4 & 117.4 \\
\hline $2.35 \mathrm{~mm}$ PM & 143.3 & 117.2 \\
\hline
\end{tabular}

Compared to the first pair of models $(2.2 \mathrm{~mm}+2.8$ $\mathrm{mm})$, the subsequent models assumed that the heat affected zone would be slightly larger, thus resulting in an increase in the fatigue crack length through this region. Since the total crack length was constant, at $5 \mathrm{~mm}$, this also suggested that the crack length through the parent material would consequently decrease. It was expected that this would lead to the number of cycles gradually increasing for HAZ models for each pair, and that it will decrease in the PM, along with its decreasing length.

The final formula that was used in order to determine the number of cycles, based on the above-mentioned parameters was [17]:

$$
N=\frac{1}{\left(\frac{m-2}{2} \cdot C \cdot f^{m} \cdot \pi^{\frac{m}{2}} \cdot \Delta \sigma^{m}\right)}\left[\frac{1}{a_{0}^{\frac{m-2}{2}}}-\frac{1}{a_{\mathrm{c}}^{\frac{m-2}{2}}}\right]
$$

\section{RESULTS}

An example of one such calculation is shown in Fig. 1, including an extract from excel file with the number of cycles formula. The actual file was divided into two images, for improved clarity. It should be noted that this excel file also takes into account the stress intensity factor critical value (fracture toughness), which can be seen in the lower left corner of the figure. In this case, $K_{\text {Ic }}$ was not necessary, since its main purpose is to determine the critical crack length. For the analysis presented here, maximum gauge length of the measuring foil was adopted as the critical crack length $(5 \mathrm{~mm})$, hence there was no need to determine $K_{\text {Ic }}$.

For the heat affected zone models, the total number of cycles was around 120000 for all three cases. The results were as follows:

- 120750 cycles for the $2.2 \mathrm{~mm}$ long HAZ fatigue crack - 120970 cycles for the $2.4 \mathrm{~mm}$ long HAZ fatigue crack - 121180 cycles for the $2.65 \mathrm{~mm}$ long HAZ fatigue crack.

The number of cycles slightly increased with crack length, with differences in hundreds of cycles, which implies a small order of magnitude $(0.17 \%)$. Thus, it can be seen that the increase in critical fatigue crack length did not have any meaningful effect on the total number of cycles for the given increases in length (around $0.2 \mathrm{~mm}$ ).
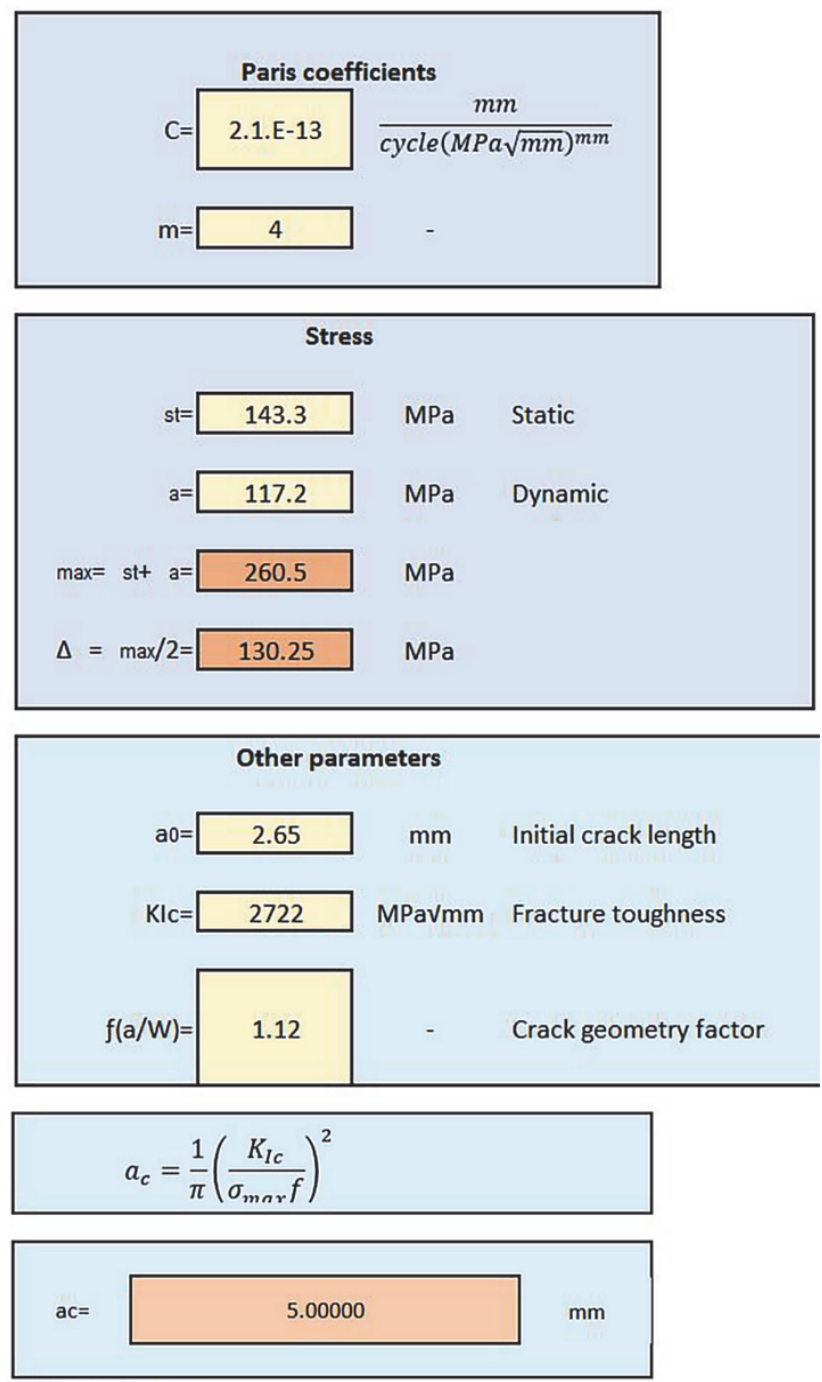

Number of cycles

$$
N=\frac{1}{\left(\frac{m-2}{2} C f^{m} \pi^{\frac{m}{2}} \cdot \Delta \sigma^{m}\right)}\left[\frac{1}{a_{0}^{\frac{m-2}{2}}}-\frac{1}{a_{c}^{\frac{m-2}{2}}}\right]
$$

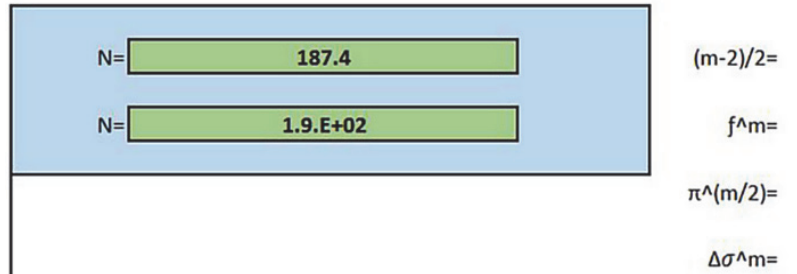

Figure 1 An example of the excel file used for the analytical calculation of the number of cycles, for model PM $2.35 \mathrm{~mm}$

As for the parent material models, the number of cycles decreased with the crack length in each subsequent model, showing the same trend as the HAZ models, but in the opposite direction. This was expected, since the heat affected zone had shown significantly higher resistance to fatigue crack growth than the parent material. Results in this case were as follows:

- 264 cycles for the $2.8 \mathrm{~mm}$ long PM fatigue crack (2.2 - $5 \mathrm{~mm}$ crack growth) 
- $\quad 228$ cycles for the $2.6 \mathrm{~mm}$ long PM fatigue crack (2.4 - $5 \mathrm{~mm}$ crack growth)

187 cycles for the $2.35 \mathrm{~mm}$ long PM fatigue crack (2.65 - $5 \mathrm{~mm}$ crack growth).

Significant differences between the two groups of models can be seen. The numbers of cycles for the parent material in this case ranged from 187 - 264, being noticeably lower than for the first group of models (HAZ). However, the relative differences in the number of cycles were much greater compared to the HAZ models. Since $\mathrm{PM}$ is weaker in terms of resistance to fatigue crack growth, as can be seen from the values of the experimentally determined Paris law coefficients, $C$ and $m$ [10], this was expected. The fact that this model had greater initial crack lengths certainly did not help matters, either.

These results are also shown in the form of crack length vs number of cycles $(a-N)$ diagrams, which can be seen in Fig. 2 to Fig. 5. For the heat affected zone models, only one of the diagrams is shown. This was done for the simple reason that the differences between the numbers of cycles for each model were so small that they could not be properly observed on the diagrams, due to their scale.

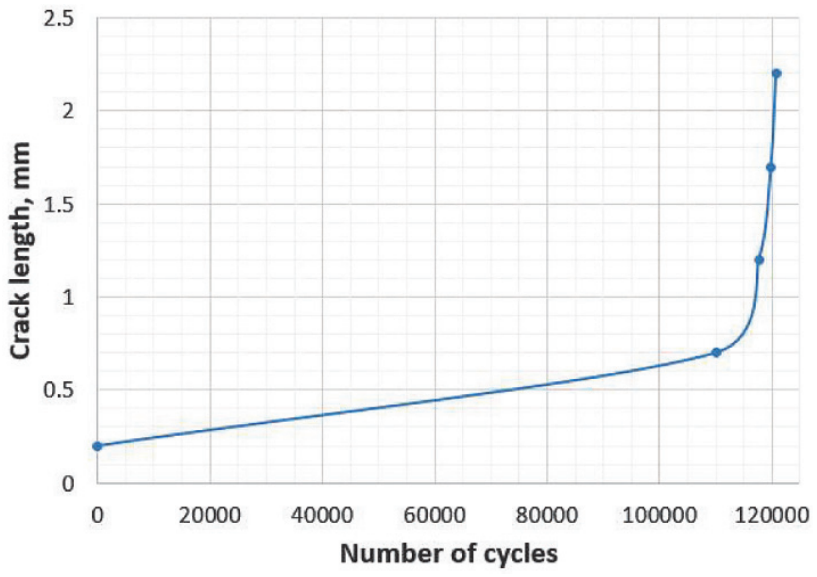

Figure 2 Crack length vs number of cycles diagram for HAZ model $(2.2 \mathrm{~mm}$ crack length)

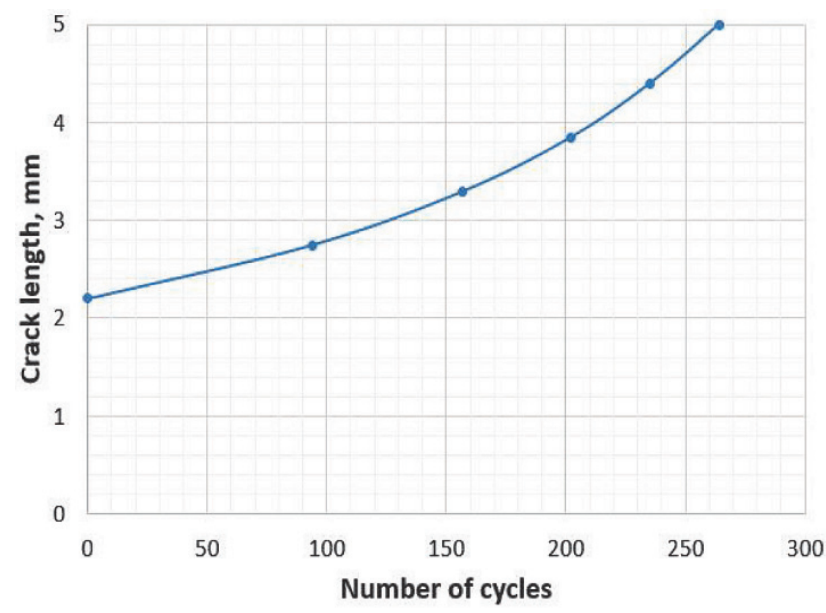

Figure 3 Crack length vs number of cycles diagram for PM model $(2.8 \mathrm{~mm}$ crack length)

These diagrams were constructed based on the same procedure as shown in Fig. 1. The number of iterations between the initial and final crack lengths were taken into account, usually at $\sim 0.5 \mathrm{~mm}$ crack length increments, resulting in a total of 5 - 6 iterations for each case.

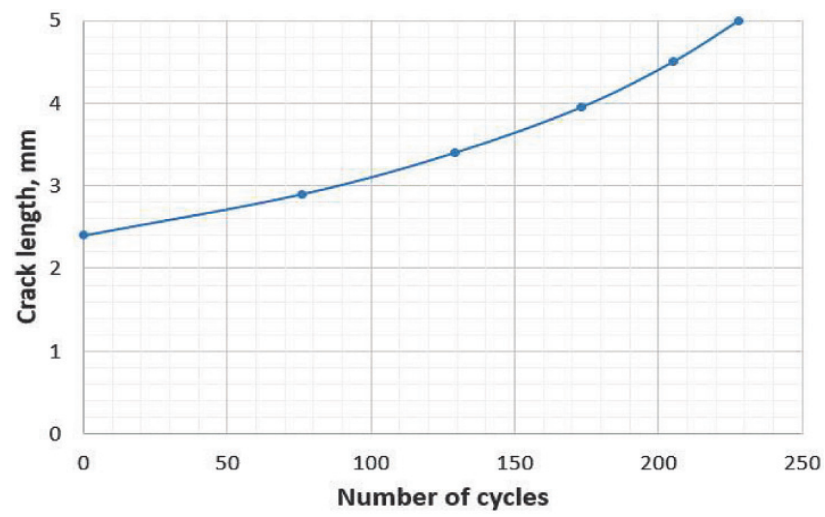

Figure 4 Crack length vs number of cycles diagram for PM model $(2.6 \mathrm{~mm}$ crack length)

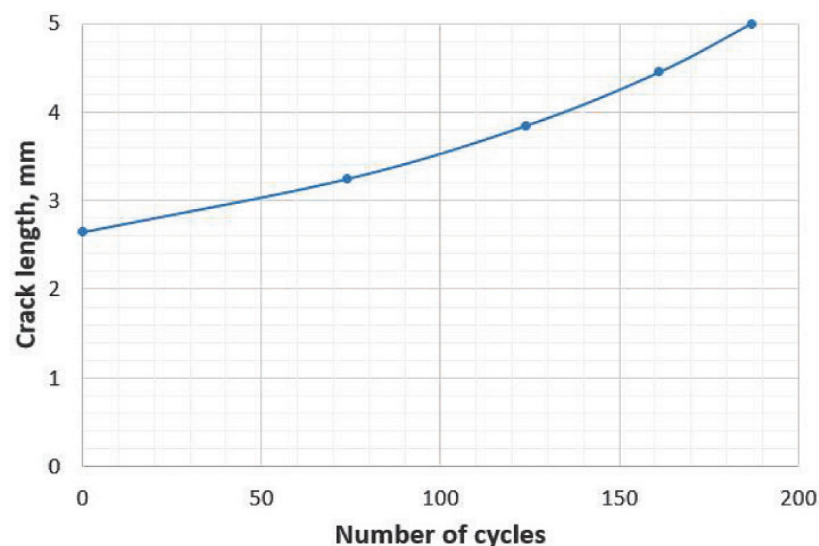

Figure 5 Crack length vs number of cycles diagram for PM model $(2.35 \mathrm{~mm}$ crack length)

\section{NUMERICAL MODELS}

Numerical simulations were performed using extended finite element method [18-22], which represents a powerful tool for fatigue simulation. All simulations were performed in ANSYS R19.2 software. Six models (three pairs of HAZ and PM with varying crack length) were made, and the loads and boundary conditions corresponding to the experiment were defined. Each model was fixed on one end, with a total of $1 \mathrm{~mm}$ length of the fixed support, and the load was defined as the bending moment (taken from the fractomat used in the experiment), which was applied on the opposite end of the model. The crack was positioned in the tip of the $1.4 \mathrm{~mm}$ notch. Finite element mesh was defined in the usual waywith finer elements concentrated around the crack tip, in the area where the highest stresses/strains were expected.

The geometry of the specimen models is shown in Fig. 6 , for one of the combinations (2.2 $\mathrm{mm} \mathrm{HAZ}+2.8 \mathrm{~mm} \mathrm{BM})$, including the cracks, which can be seen in the specimen centre, at the notch location. Standard dimensions of $10 \times 10$ $\times 55 \mathrm{~mm}$ were used in this case. Different colour regions denote sections into which the model was defined-one end section was used to define the boundary conditions, the other was used for the load; the central section was defined as the crack domain, in order to simplify the calculation, under the assumption that the crack will propagate in the same, vertical direction (like in the experiment). An example of a numerical model, with the mesh refined around the crack tip, can be seen in Fig. 6. The finite element mesh, obtained after several iterations to ensure proper result convergence, is shown in Fig. 7. 

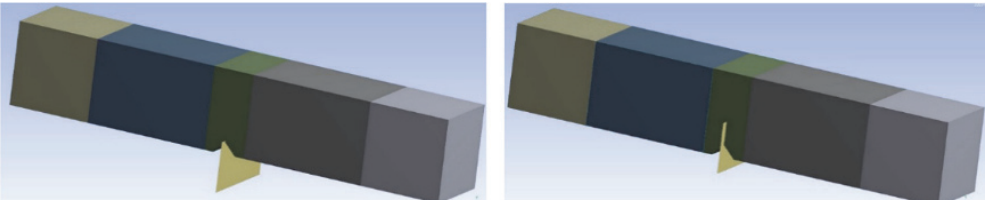

Figure 6 Model geometries (including the crack) for $2.2 \mathrm{~mm} \mathrm{HAZ} \mathrm{crack} \mathrm{(initial} \mathrm{crack} \mathrm{length} 0.2 \mathrm{~mm}$, top image) and $2.8 \mathrm{~mm}$ PM crack (initial crack length of $2.2 \mathrm{~mm}$ bottom image)

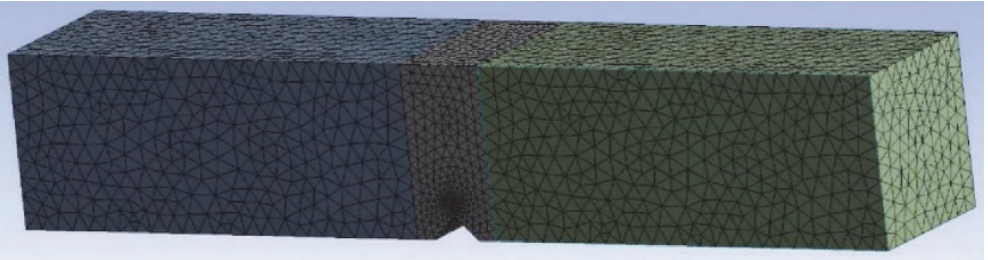

Figure 7 Finite element mesh used for the models

\section{COMPARISON WITH THE NUMERICAL ANALYSIS}

In this section of the paper, the comparison between the analytically and numerically obtained results will be presented. The overview of these results is shown in Tab. 2 and Tab. 3, for analytical and numerical results, respectively.

Table 2 Analytical number of cycles results
\begin{tabular}{|c|c|c|c|}
\hline $\begin{array}{c}\text { HAZ fatigue } \\
\text { crack }\end{array}$ & Number of cycles & PM fatigue crack & $\begin{array}{c}\text { Number of } \\
\text { cycles }\end{array}$ \\
\hline $2.2 \mathrm{~mm}$ & 120,750 & $2.8 \mathrm{~mm}$ & 264 \\
\hline $2.4 \mathrm{~mm}$ & 120,970 & $2.6 \mathrm{~mm}$ & 228 \\
\hline $2.65 \mathrm{~mm}$ & 121,180 & $2.35 \mathrm{~mm}$ & 187 \\
\hline
\end{tabular}

Table 3 Numerical number of cycles results

\begin{tabular}{|c|c|c|c|}
\hline $\begin{array}{c}\text { HAZ fatigue } \\
\text { crack }\end{array}$ & Number of cycles & PM fatigue crack & $\begin{array}{c}\text { Number of } \\
\text { cycles }\end{array}$ \\
\hline $2.2 \mathrm{~mm}$ & 51,160 & $2.8 \mathrm{~mm}$ & 2,400 \\
\hline $2.4 \mathrm{~mm}$ & 51,180 & $2.6 \mathrm{~mm}$ & 2,310 \\
\hline $2.65 \mathrm{~mm}$ & 51,900 & $2.35 \mathrm{~mm}$ & 2,260 \\
\hline
\end{tabular}

For comparison purposes, the $a-N$ diagrams obtained by the numerical simulation are also shown in Fig. 8 to Fig. 13.

Certain differences can be observed in the maximum values for crack length and number of cycles on the diagrams, when compared to the values shown in Tab. 3.

This was due to the fact that the numerical crack length could not be limited to precisely $2.2 \mathrm{~mm}, 2.4 \mathrm{~mm}$, etc. (this was the reason for the $2.35+2.65 \mathrm{~mm}$ combination-crack length cannot be strictly defined and is determined by the number of sub-steps in the fatigue analysis). For this reason, the number of cycles corresponding to these "round" values was determined by interpolation. Since the differences between real and round crack lengths were very small, the part of the curve between them could be observed as linear, hence determining the ratio between these two lengths and multiplying the number of cycles with it was sufficiently accurate for determining the exact number of cycles.

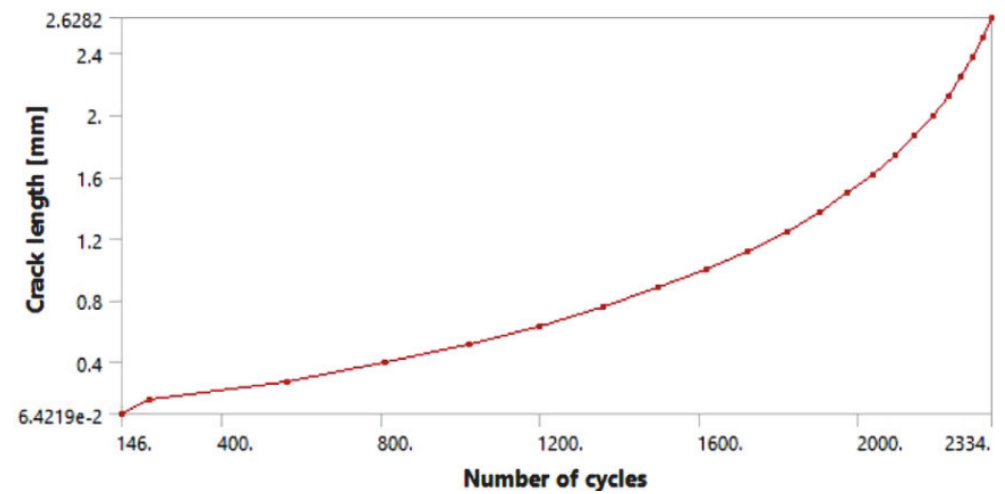

Figure 8 Crack length vs number of cycles diagram for PM model ( $2.6 \mathrm{~mm}$ crack length), numerical result

Based on the results for all three heat affected zone models, it was clear that the differences were negligible, as the models differed by around 200 cycles between subsequent lengths. In relative terms, this difference was around $0.18 \%$ between HAZ 2.2 and HAZ 2.4 mm models, and $0.17 \%$ between HAZ 2.4 and HAZ $2.65 \mathrm{~mm}$ models. For the parent material models, on the other hand, the differences were considerably higher, in terms of percentage (much lower in absolute values, but the numbers were several orders of magnitude lower to begin with). More accurately, the first two models, PM $2.8 \mathrm{~mm}$ and PM $2.6 \mathrm{~mm}$ (corresponding to the HAZ 2.2 and HAZ $2.4 \mathrm{~mm}$ models, respectively) showed a difference of $13.6 \%$ (which is almost 100 times greater than their HAZ counterparts). The difference between the second two (PM $2.6 \mathrm{~mm}$ and PM $2.35 \mathrm{~mm}$ ) was even greater, this time around $18 \%$. This was in accordance with what was previously stated about the fatigue crack growth resistance of both welded joint regions and the initial conditions. 


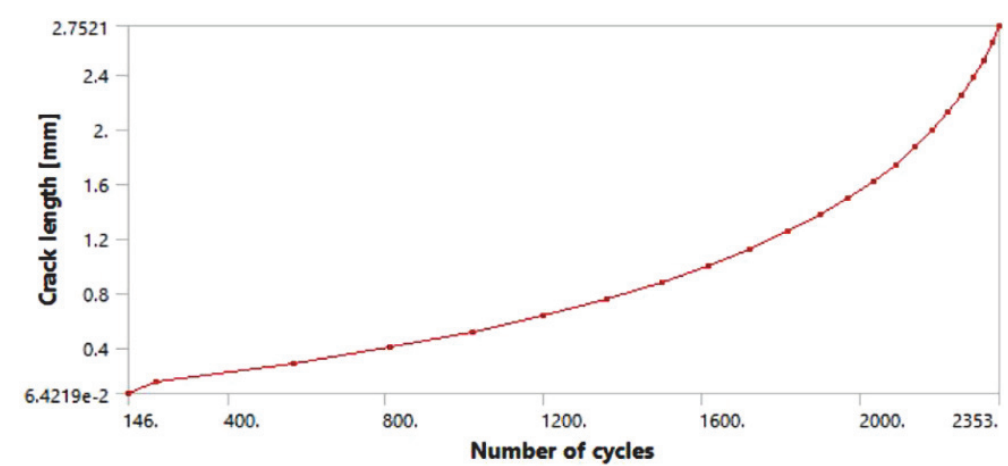

Figure 9 Crack length vs number of cycles diagram for PM model ( $2.8 \mathrm{~mm}$ crack length)

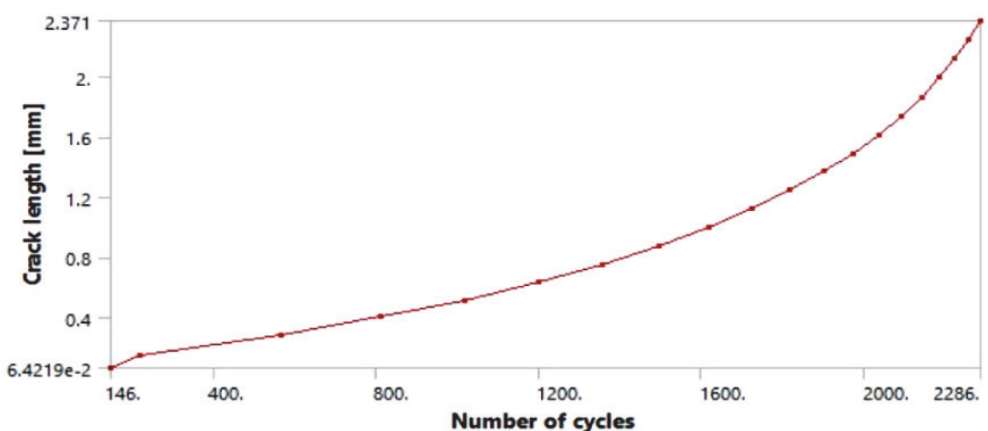

Figure 10 Crack length vs number of cycles diagram for PM model ( $2.35 \mathrm{~mm}$ crack length)

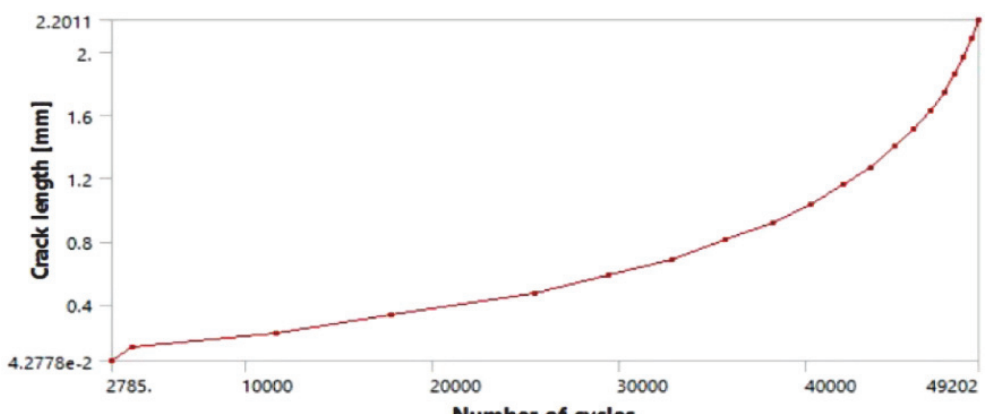

Figure 11 Crack length vs number of cycles diagram for HAZ model ( $2.2 \mathrm{~mm}$ crack length)

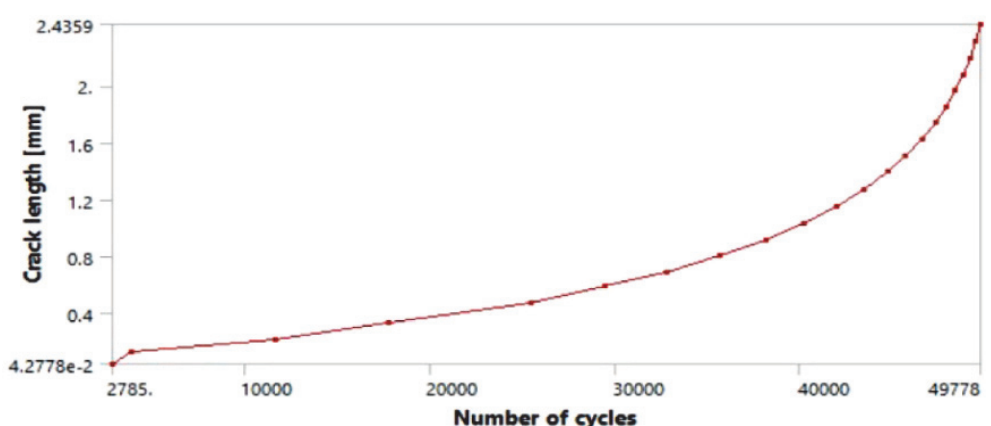

Figure 12 Crack length vs number of cycles diagram for HAZ model (2.4 mm crack length)

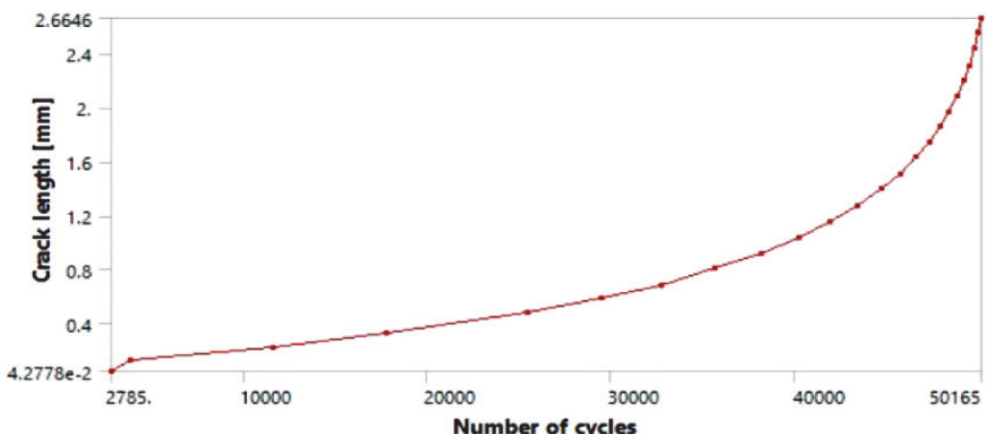

Figure 13 Crack length vs number of cycles diagram for HAZ model ( $2.65 \mathrm{~mm}$ crack length) 


\section{DISCUSSION}

The above resulted in a considerable increase in the difference, which was already expected to be of significant order of magnitude, based on the experimentally determined values of the Paris coefficients for the heat affected zone and the parent material, the same that were used in both numerical and analytical analyses. When observed in total, for a length of $5 \mathrm{~mm}$, these differences were also negligible, since the PM number of cycles was almost 600 times lower, and their high relative differences were negligibly small on the global scale. It was observed for HAZ differences, which were very small from the beginning, and as a result, their sums barely changed, although they still marginally increased with the increase of crack length in the stronger, heat affected zone.

Regarding the numerical results, some interesting observations can be made. The numbers of cycles in this case were also much higher for the HAZ, being slightly above 50000 for the HAZ models, compared to the PM models, where these numbers were around 2300. Significantly, higher resistance to fatigue crack growth in this case can be simply explained by the fact that the input fatigue parameters, i.e. Paris coefficients, were the same. Based on this, it can be seen that, for the heat affected zone models, the analytical calculations provided numbers of cycles more than twice greater than the numerical models, and that the differences between individual HAZ numerical models were also quite small, around $1 \%$ or even less.

Things get interesting for the parent material models, since the situation was reversed-the numerically obtained numbers of cycles were 8 - 10 times greater than the analytically obtained ones, between individual models. As for the differences between analytical/numerical models of different crack lengths, the percentage increase/decrease in the number of cycles is significantly higher in the case of analytical results, despite obviously lower values. For numerical results, these differences ranged from $2.2-3.75 \%$, around 5 - 6 times less than the analytical differences.

As was determined, differences between the two welded joint regions (the heat affected zone and the parent material) were far more prominent in the case of analytical calculation, with HAZ models having $~ 600$ times greater cycle numbers, as opposed to the numerical ones, where these numbers were "only" 25 times greater. The behaviour of the heat affected zone and the parent material in terms of resistance to fatigue crack growth remained the same in both cases-the heat affected zone performed in accordance with the expectations based on experimental work-it had shown much higher fatigue life in both analytical and numerical analyses.

In terms of the total number of cycles for each pair of HAZ and PM models, which were adopted in the same way in both cases (i.e. $2.2+2.8 \mathrm{~mm}, 2.4+2.6 \mathrm{~mm}$ and $2.65+$ $2.35 \mathrm{~mm}$ combinations), the differences were very small.

\section{CONCLUSIONS}

This research involved the comparison between numerical and analytical calculations of fatigue life of welded joints, with special focus on how the crack propagates through different welded joint region. In order to obtain a more detailed insight, different crack length combinations, for heat affected zone and parent material were adopted, and potential differences between them were observed. In terms of total number of cycles (for both zones combined), changing the fatigue crack length by amounts around $\sim 0.2 \mathrm{~mm}$ did not make a noticeable difference, and similar trends were observed for the HAZ models. For the PM models, relative differences were much greater, but the number of cycles was significantly lower. While most of the results had shown a solid degree of similarity, there was still a part of the investigation that resulted in questions which should be dealt with during future research was related to the difference in the behaviour of "numerical" and "analytical" fatigue cracks in the parent material, compared to their heat affected zone counterparts. It was expected that both regions either have smaller or greater fatigue life in the case of analytical calculation, compared to the numerical, but this was reversed for the PM.

This suggests that additional analyses should be undertaken as future research, to try and determine why such different behaviour was obtained for different welded joint regions. This also suggests the need to thoroughly reconsider the adopted approximation, so that these models could be further improved at some point.

There are additional directions in which this research can be taken, using the models and results presented here as the base. This involves the application of the developed methodology to materials which actually "make sense" from the viewpoint of fatigue. Another conclusion that can be drawn from the presented work is that relatively small changes in fatigue crack length did not make any noticeable global differences in terms of fatigue life, which suggests that future analyses should assume bigger differences in crack lengths. This, on the other hand suggests that the geometry of each welded joint should also change considerably, to explain such increases/decreases in crack length. Finally, it can be concluded that this approach would make sense when comparing welded joints made of the same material, but with different weld groove geometries.

\section{Acknowledgement}

The authors would like to thank the Ministry of Education, Science and Technological Development of the Republic of Serbia for the support of project TR 35040.

\section{REFERENCES}

[1] Sedmak, S. A., Burzić, Z., Perković, S., Jovičić, R., Aranđelović, A., Radovic, Lj., \& Ilic, N. (2019). Influence of welded joint microstructures on fatigue behaviour of specimens with a notch in the heat affected zone. Engineering Failure Analysis, 106. https://doi.org/10.1016/j.engfailanal.2019.104162

[2] Medjo, B., Rakin, M., Gubeljak, N., Matvienko, Y., Arsic, M., Sarkocevic, Z., \& Sedmak, A. (2015). Failure resistance of drilling rig casing pipes with an axial crack. Engineering Failure Analysis, 58(2), 429-440. https://doi.org/10.1016/j.engfailanal.2015.05.015

[3] Milović, Lj., Vuherer, T., Radaković, Z., Petrovski, B., Janković, M., Zrilić, M., \& Daničić, D. (2011). Determination of fatigue crack growth parameters in welded joint of HSLA steel. Structural Integrity and Life, 11(3), 183-187.

[4] Rakipovski, E., Grbović, A., Kastratović, G., \& Vidanović, N. (2015). Application of extended finite element method for fatigue life. Structural Integrity and Life, 15(1), 3-6. 
[5] Aleksić, V., Milović, Lj., Aleksić, B., Bulatović, S,. Burzić, Z., \& Hemer, A. (2017). Behaviour of Nionikral-70 in low-cycle fatigue. Structural Integrity and Life, 17(1), 61-73.

[6] Kraedegh, A., Li, W., Sedmak, A., Grbović, A., Trišović, N., Mitrović, R., \& Kirin, S. (2017). Simulation of fatigue crack growth in A2024-T351 T-welded joint. Structural Integrity and Life, 17(1), 3-6.

[7] Jovanović, M., Čamagić, I., Sedmak, S. A., Živković, P., Sedmak, A. (2020). Crack Initiation and Propagation Resistance of HSLA Steel Welded Joint Constituents. Structural Integrity and Life, 20(1), 11-14.

[8] Durdevic, A., Zivojinovic, D., Grbovic, A., Sedmak, A., Rakin, M., Dascau, H., \& Kirin, S. (2015). Numerical simulation of fatigue crack propagation in friction stir welded joint made of Al 2024-T351 alloy. Engineering Failure Analysis, 58(2), 477-484. https://doi:10.1016/j.engfailanal.2015.08.028

[9] Sghayer, A., Grbović, A., Sedmak, A., Dinulović, M., Doncheva, E., \& Petrovski, B. (2017). Fatigue Life Analysis of the Integral Skin-Stringer Panel Using XFEM. Structural Integrity and Life, 17(1), 7-10.

[10] Gubeljak, N. (1999). Fracture behaviour of specimens with surface notch tip in the heat affected zone (HAZ) of strength mis-matched welded joints. International Journal of Fracture, 100, 155-167. https://doi.org/10.1023/A:1018794316336

[11] Gubeljak, N., Predan, J., Kozak, D., Tuma, J., Kovačič, B., Konjatić, P., \& Sertić, J. (2009). An Estimation of Sufficient Impact Toughness for the Material of a Turbine Shaft. Strojarstvo, 51(4), 263-271.

[12] Sertic, J., Samardzic, I., Kozak, D., et al. (2015). Influence of fatigue impact loading on radial carrier and rapping device fillet weld strength. Technical Gazette, 22(2), 547-555. https://doi.org/10.17559/TV-20141022092231

[13] Novoselac, S., Kozak, D., Ergic, T., et al. (2014). Fatigue of Shaft Flange Bolted Joints under Preload Force and Dynamic Response. FME Transactions, 42(4), 269-276. https://doi.org/10.5937/fmet1404269n

[14] Cabrilo, A. \& Geric, K. (2016). Weldability of High Hardness Armor Steel. Advanced Materials Research, 1138, 79-84. https://doi.org/10.4028/www.scientific.net/AMR.1138.79

[15] Prokić-Cvetković, R., Kastelec-Macura, S., Milosavljević, A. Popović, O., \& Burzić, M. (2010).The effect of shielding gas composition on the toughness and crack growth parameters of AlMg4,5Mn weld metals. J. Min. Metall. Sect. B-Metall., 46(2)B, 193-202. https://doi.org/10.2298/JMMB1002193P

[16] Arsić, M., Karić, R., Sedmak, A., Burzić, M., \& Vistać, B. (2013). Methodological approach to integrity assessment and service life of rotating equipment at hydropower plant-turbine shaft. Structural Integrity and Life, 13(2), 117-124.

[17] Kocak, M. et al. (2008). FITNET Fitness-for-service (FFS) Annex-Vol. 2, GKSS Research Centre Geesthacht.

[18] Jovičić, G., Živković, M., Sedmak, A., Jovičić, N., \& Milovanović, D. (2010). Improvement of algorithm for numerical crack modelling. Archives of Civil and Mechanical Engineering, 10, 19-35. https://doi.org/10.1016/S1644-9665(12)60134-4

[19] Sedmak, A. (2018). Computational fracture mechanics-an overview from early efforts to recent achievements. FFEMS, 41(12), 2438-2474.https://doi.org/10.1111/ffe.12912

[20] Milovanović, N., Sedmak, S., Arsić, M., \& Božić, Z. (2020). Structural integrity and life assessment of rotating equipment. Engineering Failure Analysis, 113. https://doi.org/10.1016/j.engfailanal.2020.104561

[21] Džindo, E., Sedmak, S., Grbović, A., Milovanović, N., \& Đorđević, B. (2019). XFEM simulation of fatigue crack growth in a welded joint of a pressure vessel with a reinforcement ring. Archive of Applied Mechanics, 89. https://doi.org/10.1007/s00419-018-1435-1

[22] Eldwaib, K. A., Grbović, A., Kastratović, G., Radu, D., \& Sedmak, S. A. (2017). Fatigue Life Estimation of CCT
Specimen Using XFEM. Structural Integrity and Life, 17(2), 2017, 151-156.

\section{Contact information:}

Abubkr M. HEMER, M.Sc.ME, PhD student

University of Belgrade, Faculty of Mechanical Engineering,

Kraljice Marije 16, 11120 Belgrade, Serbia

E-mail: Hemer1610@gmail.com

\section{Mihajlo ARANDJELOVIĆ, Research Associate}

(Corresponding author)

Innovation Center of Faculty of Mechanical Engineering

Kraljice Marije 16, 11120 Belgrade, Serbia

E-mail: mixaylo23@gmail.com

Ljubica MILOVIĆ, PhD, Assistant Professor

University of Belgrade, Faculty of Technology and Metallurgy,

Karnegijeva 4, 11120 Belgrade, Serbia

E-mail: acibulj@tmf.bg.ac.rs

Milan KLJAJIN, PhD, Full Professor with Tenure

University North, University Center Varaždin,

Jurja Križanića 31b, 42000 Varaždin, Croatia

E-mail: mkljajin@unin.hr

Jasmina LOZANOVIĆ ŠAJIĆ, PhD, Scientific Associate Innovation Center of Faculty of Mechanical Engineering, Kraljice Marije 16, 11120 Belgrade, Serbia

E-mail: jlozanovic@mas.bg.ac.rs 